\title{
Un hindú en la sinagoga: un personaje paradójico en la 'Iggeret ha-musar de Ibn Falaquera
}

\author{
Aurora Salvatierra OsSorio * \\ Universidad de Granada
}

Entre los muchos textos que se conservan del legado intelectual del Šem Tob ibn Falaquera (ca. 1223-90), poca ha sido la atención que ha merecido uno de sus escritos más singulares: la 'Iggeret ha-musar. Editada por A.M. Haberman en el año $1936^{1}$, esta obra, que si bien por extensión puede calificarse de menor, nos descubre, tras una lectura detenida, un nada desdeñable interés en sí misma y dentro del contexto cultural del siglo XIII.

Será el propio autor quien, como en otros de sus libros, nos informe acerca de algunas de las circunstancias que rodearon su composición, en este caso, la edad temprana que afirma tener al escribirla ${ }^{2}$. La mención de la 'Iggeret ha-musar («mi conocida 'Iggeret ha-musar») en su tratado Batte hanhagat ha-nefes $\breve{3}^{3}$ permite dar credibilidad a sus palabras y afirmar que se trata de la

*aurora@ugr.es

${ }^{1}$ En Qobeș 'al yad 11, págs. 45-88. Haberman utiliza en su edición sólo uno de los dos manuscritos conservados de la 'Iggeret ha-musar (Oxford-Bodleian Library MS Opp. Add. Qu. 144, ff. 24-47), reconociendo la imposibilidad de acceder al segundo de ellos (New York, JTS, Ms. 2275); más tarde, a modo de anexo, publica un apéndice con las variantes de este segundo manuscrito (en Qobeș 'al yad 12 [1937], págs. 133-137), variantes que, según él mismo nos cuenta, Y. Davidson tuvo la gentileza de enviarle tras leer del texto publicado por él. Estas circunstancias peculiares hacen necesario una edición revisada de la 'Iggeret ha-musar que actualmente preparo. Salvo indicación, las citas que aparecen en este artículo remiten al número de página de la edición de Haberman.

2 «Mas yo que soy joven» ('Iggeret ha-musar, pág. 47).

${ }^{3}$ E. Varela Moreno, Versos para la sana conducción del cuerpo. Versos para la sana conducción del alma de Šem Tob ibn Falaquera. Trad., edición crítica y comentario (Granada 1986), págs. 105 y 51*. Desde ahora en las referencias a este texto sigo esta edición. 
primera obra de Falaquera, desmintiendo el segundo lugar que él mismo le otorga en la relación de textos que ofrece en el Sefer ha-měbbaqueš ${ }^{4}$.

Estaríamos, pues, ante la opera prima de un intelectual judío de cuya vida casi todo se ignora y cuyo pensamiento se va desvelando poco a poco y mostrándose en toda su complejidad. En este su primer ensayo literario, opta Falaquera por una forma de expresión bien conocida en la literatura hispanohebrea, la prosa rimada con intercalación de poemas, y por un contenido en el que se conjugan enseñanzas ético-morales, filosóficas, científicas, etc., como es habitual en los libros y colecciones de sentencias medievales. Como ya el título sugiere, estamos ante un texto sapiencial cuya finalidad es la de enseñar los fundamentos que han de regir la vida humana y el modo en que ésta ha de adaptarse a los diversos ámbitos en que se desarrolla con el fin de formar hombres sabios e instruidos. Para ello Falaquera escoge una estructura narrativa bien conocida en su tiempo: los sucesivos encuentros del joven Calcol con diversos sabios en pos del conocimiento y la sabiduría ${ }^{5}$. En esta ocasión tres son los personajes elegidos para acompañarle en su viaje iniciativo: un maestro judío (Hemán) ${ }^{6}$, uno procedente de Arabia y un tercero de la India, estos dos últimos sin nombre propio ${ }^{7}$. Cada uno de ellos brinda a Falaquera la posibilidad de ir inculcando a su protagonista (y a través de él a su público) una serie de enseñanzas heterogéneas tanto con sus palabras como

${ }^{4}$ Se cita a partir de ahora según la edición de Varsovia 1924 y, en su caso, la traducción inglesa de H. LEvine, The Book of the Seeker (Sefer ha-mebaqqesh) by Shem Tob ben Joseph ibn Falaquera. Trans. and edited (New York 1976). Sobre la cronología de las obras de Falaquera véase R. Jospe, Torah and Sophia: The Life and Thought of Shem Tov ibn Falquera (Cincinnati 1988) pág. 31 ss.

${ }^{5}$ El mismo Falaquera volverá a recurrir a un esquema semejante en el Sefer haměbbaqueš si bien en esta obra el «buscador» no solo aprenderá de los saberes de sus interlocutores sino, y sobre todo, de sus errores o ausencia de conocimientos.

${ }^{6}$ No pasa desapercibida la complicidad que busca Falaquera con sus lectores al otorgar a los dos protagonistas judíos de su texto los nombres de Hemán y Calcol, ambos personajes habituales en los relatos hispanohebreos. Su sola mención contribuye a captar y despertar el interés de los destinatarios de la obra; de modo similar actúan, por ejemplo, Alejandro y Aristóteles, Platón o Sócrates en la prosa sapiencial castellana del XIII donde el recurso a ciertos nombres es clave en su éxito.

${ }^{7}$ Tal vez exista un cierto eco en estos tres sabios de los tres filósofos más citados en las obras de origen oriental que se popularizan en la literatura del XIII: Sócrates, Platón y

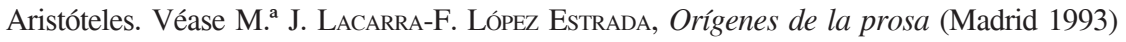
pág. 40 ss. 
con sus actos; cada uno de ellos incorpora dentro del texto modelos de conocimiento y conducta diversos que, en más de una ocasión, no pueden por menos que sorprender al lector e incluso provocarle cierto desconcierto. Y en este sentido, el sabio hindú ocupa el lugar más destacado. Es cierto que, a primera vista, la procedencia del personaje no debía resultar especialmente llamativa: a lo largo del siglo XIII se están difundiendo por la península no pocas obras de origen oriental, salpicadas de elementos orientales, con la India como escenario (piénsese en el comienzo de Barlaam y Josafat) o como meta del saber (así en Sendebar o en el Calila y Dimna). Pero el tratamiento que en la 'Iggeret ha-musar se da al hindú dista mucho, en mi opinión, de ser un lugar común, un mero reflejo de convenciones de la época.

\section{El ENCUENTRO CON El SABio (DE LA India)}

El encuentro de Calcol con este personaje se produce una vez ha recibido las primeras enseñanzas de Hemán, quien le acompaña hasta el fin del relato, y tras haber dialogado brevemente con el sabio árabe. Una vez concluido este segundo encuentro, Hemán marcha con Calcol al jardín de su casa, un entorno paradisíaco que recuerda los jardines que pueblan la poesía hebrea de al-Andalus. Este marco, que juega un papel clave en la 'Iggeret ha-musar, actúa dentro del texto como un espacio simbólico del que Falaquera se vale, entre otras cosas, para hacer frente a ciertos modelos de ascetismo que parece no juzgar acertados ${ }^{8}$. Manejando con habilidad el lenguaje y propiciando asociaciones con el entorno cortesano que la poesía del siglo de Oro recreó en sus versos, Falaquera seduce a sus lectores con una larga velada dentro del jardín donde no falta el vino, la comida, la naturaleza exuberante o el canto de los pájaros ${ }^{9}$.

\footnotetext{
${ }^{8}$ En este sentido destaca el contraste entre el mensaje de renuncia que el maestro de Arabia pronuncia en el campo junto a un arroyo y la llamada al goce de los sentidos que inmediatamente después Hemán entona en el jardín de su casa. Véase 'Iggeret ha-musar, págs. 68-71.

${ }^{9}$ Solo la ausencia del elemento erótico y amoroso marca una clara (e intencionada) frontera con la réplica del jardín cortesano andalusí que aquí se evoca. Una circunstancia similar ha sido señalada respecto al Minḥat Yěhudah de ibn Šabběttay. Véase T. Rosen, «Sexual Politics in a Medieval Hebrew Marriage Debate», Exemplaria 12,1 (2000) págs 157-184: pág. 164 ss.
} 
La placidez del momento se rompe bruscamente cuando al salir de allí se encuentran de modo inesperado con un anciano sabio pero pobre [Ecl 9: 15], con harapos raídos por vestido [Jr 38: 11], tierra sobre la cabeza [1 Sm 4: 12], con su rostro ensombrecido, sin hermosura ni esplendor [Is 53: 2] ${ }^{10}$.

Maestro y discípulo van a incurrir entonces en una conducta reprobable: Negarse a devolverle el saludo ${ }^{11}$. Esta actuación propicia la primera enseñanza del sabio sobre el buen recibir y el peligro de juzgar por la apariencia, cuestiones ambas que forman parte de la instrucción cívico-ética que se recoge en los compendios de castigos medievales donde las buenas maneras y el buen talante son parte del perfil ideal del individuo ${ }^{12}$.

$\mathrm{El}$ anciano reacciona con dureza ante esta mala conducta que recrimina con palabras que, al menos en su inicio, habrían de facilitar su identificación con el oráculo de condena de los profetas bíblicos:

«Entonces les dijo: ¡Ay de los que se creen sabios y entendidos! [Is 5: 21], ¿de qué les sirve la sabiduría? [Jer 8: 9]» ${ }^{13}$.

Tras este guiño a sus lectores hebreos, versos y dos exempla ilustran su invectiva y nutren su discurso ejemplificando y adornando la exposición:

Contaron que un hombre entró a casa de un rey; llevaba harapos raídos pero habló ante él con corrección. Entonces el rey le dijo: Si hubieran sido tan buenas tus ropas como buenas son tus palabras habrías dado (tanto a tu cuerpo como) a tu alma su recompensa ${ }^{14}$. Y le dijo: Mi señor

\footnotetext{
10 'Iggeret ha-musar, pág. 71.

${ }^{11}$ Nótese que a la luz de su conducta tampoco Hemán ha alcanzado el buen comportamiento que aspira a enseñar por lo que, momentáneamente, se convierte, junto con Calcol, en un contramodelo.

${ }_{12}$ Valgan a modo de muestra las sentencias recogidas al respecto en el Libro de los cien capítulos, pág. 125 ss. (cito según la edición de M. Haro Cortés, Libro de los cien capítulos, Frankfurt-Madrid 1998) o en Bocados de Oro, pág. 134, 11. 60 ss. (según página y línea del texto crítico de M. PArker, Text and Concordance of Bocados de Oro. BNM I-187. Madison 1993 [Microf.]). Honrar al otro según su sabiduría y no su vestido y su aspecto es también tema central del capítulo VIII de Ben ha-melek wĕ-ha-nazir de Ibn Hasday (texto hebreo A. M. Haberman, Sefer Ben ha-melek wĕ-ha-nazir, Tel-Aviv 1950; traducción catalana T. CAlders, El Princep i el Monjo, Barcelona 1987).

13 'Iggeret ha-musar, pág 71.

${ }^{14}$ Pues como el alma ha sido agraciada con la sabiduría, el cuerpo lo hubiera sido con ropas dignas.
} 
rey, tu tienes poder sobre las vestiduras pero yo sobre las palabras. Y ordenó el rey darle ropajes ${ }^{15}$.

Y contaron que un rey pasó junto a un sabio y estaba el rey vestido con ropajes de seda y brocados de oro. El rey lo humilló y el sabio le dijo: Tu te engríes por algo que no es de tu misma especie, mas vuelve toda especie a su especie, ¡acuérdate de lo que estamos hablando! Y vio un joven de muy buena apariencia pero que no tenía entendimiento y dijo: ¡Qué hermosa es esta casa pero no tiene cimientos ${ }^{16}$ !

Pocas líneas han bastado a Falaquera para convertir a quien apareció en escena como un mendigo harapiento en un airado censor que con su discurso atemoriza a sus interlocutores ${ }^{17} \mathrm{y}$ los mueve a solicitar su perdón, un perdón que se les concede sin reticencias. Textos como el Mibhar ha-pěninim ${ }^{18}$ o Tiqqun ha-nefe $\check{S}^{19}$ pudieron proporcionarle al autor algunas de las máximas que utiliza para ponderar la virtud de la compasión y la indulgencia. Pero, al margen de las fuentes utilizadas, creo interesante tener en cuenta que estas cualidades no son ajenas al modelo de gobernante (e indirectamente de individuo) que en el XIII se está proponiendo en los compendios de castigos, un modelo en el que la actitud benevolente es expresión de sabiduría y prudencia ${ }^{20}$.

${ }^{15}$ El mismo relato se encuentra en Musre ha-filosofim II, 5: 16 (cito esta obra según sección, capítulo y epígrafe de la edición de A. LoewentHal, Musre ha-filosofim, Frankfurt 1896). También se recoge en la versión castellana Libro de los buenos proverbios, pág. 103 (ed. H. Sturm, The Libro de los buenos proverbios, Lexington 1971). En ambas obras el rey anónimo de Falaquera se identifica con Alejandro.

16 'Iggeret ha-musar, pág. 72. Sigo en la traducción de este exemplum el manuscrito Ms. 2275 del JTS-New York que hace innecesarias las correcciones introducidas por Haberman en su edición. Otras versiones de este dicho sapiencial pueden verse en Libro de los buenos proverbios, pág. 138 o Bocados de Oro, pág. 45 11. 75 ss. donde se pone en boca de Diógenes.

17 «Temieron uno al otro y de la espada de su lengua tuvieron miedo» ('Iggeret hamusar, pag. 73).

18 Véase D. Gonzalo MAeso, Šělomoh ibn Gabirol. Selección de perlas. Versión española con introducción y notas (Barcelona 1977), especialmente el capítulo IV.

19 J. Lomba Fuentes, La corrección de los caracteres de Ibn Gabirol. Introducción, traducción y notas (Zaragoza 1990), págs. 99-100.

${ }^{20}$ Una muestra de ello puede leerse, entre otros muchos textos, en el Libro de los cien capítulos (pág. 86) o en el Libro de los buenos proverbios (págs. 93-94) entre los consejos que Aristóteles da a Alejandro. 


\section{En CASA DE Hemán: ¿UN MAESTRO hiPócrita?}

El interior de la casa de Hemán es el escenario que Falaquera elige para seguir desarrollando su relato. Hasta ella han llegado, sin dejar de escuchar reproches del anciano ${ }^{21}$, para agasajarlo con una comida en la que no falta una copa de cristal llena de vino. Este detalle, en principio sin mayor relevancia, es el motivo que articula la «extraña» conducta del anciano quien se niega a comer. La causa, según el mismo nos explica, es la similitud del cristal con aquél que no sabe guardar un secreto, algo que el bien conoce por propia experiencia:

Tenía yo un mal vecino, quien se vengó de la generación del diluvio se vengue de él $[B M 84 b]$, y solía descubrirle secretos pues pensaba que los guardaría en su corazón como (quien) esconde su pecado en su seno [Job 31: 33], como escondería el avaro su oro y su plata; pero pasado un tiempo los descubrió y mostró a todos sus secretos hasta que juré que no mantendría mi amistad; el que anda con chismes revela el secreto [Prov 11: 13] y el cristal es de los chismosos como han dicho los que cuentan parábolas, pues no oculta lo que ponen en él como el chismoso no oculta lo que hay en su corazón ${ }^{22}$.

Con esta anécdota la integridad del sabio se lleva hasta un extremo un tanto hiperbólico (en cierto sentido, se roza lo caricaturesco) al tiempo que se facilita la inserción de una serie de enseñanzas en torno al hecho de guardar y respetar los secretos que a uno le han sido confiados ${ }^{23}$. Sin duda, el «mal vecino» se ha comportado erróneamente, sin juicio, pero es posible detectar una sombra de necedad en el sabio pues si importante es en este ámbito ejemplar no desvelar lo oculto, no menos lo es el sopesar bien en quien ha de confiarse ${ }^{24}$.

${ }^{21}$ «Y les hablaba a ellos con claridad y les reprendía con toda clase de reproches» ('Iggeret ha-musar, pág. 73).

22 'Iggeret ha-musar, págs. 73-74.

${ }^{23}$ Es esta una de las cualidades que dibujan el perfil moral del individuo en la prosa sapiencial del XIII y que, como tantas otras, se acepta y aplica en obras árabes, hebreas y castellanas.

24 Basta repasar la literatura didáctica de la época para comprobar lo virtuoso de examinar a quién se descubre la poridat. Valga como ejemplo este fragmento tomado del capítulo XXVIII de Los castigos del rey D. Sancho (edición, introducción y notas H. O. Bizzarri, Madrid 2001: pág. 224: «Mio fijo, mete mientes e guárdate a qué omne dizes o descubres tu poridat. E para seer bien guardado desto ha menester que de primero metas mientes en dos cosas. La primera, en quál es la poridat (...): La segunda cosa, quál es el omne a quien la quieres decir, e cómmo es ya probado en otras poridades $(\ldots)$ ». 
No obstante, Falaquera nos ha situado como lectores ante un personaje de conducta irreprochable (al menos en apariencia) capaz de renunciar al banquete que se le ofrece por la simple presencia de una copa de cristal que Hemán se apresura a cambiar. Y una vez ésta es sustituida por vasos de plata «comió el anciano cuanto le pusieron delante y dijo que le pusieran más» ${ }^{25}$. Lo que se cuenta no puede menos que desconcertar pues, en un instante, con una sola línea, la imagen de asceta del personaje se ha desvanecido. Ante esta conducta sin rastro de la moderación que cabría esperar de él, Calcol interviene de un modo brusco y airado, con una reacción que bien podría reflejar la de los destinatarios el texto:

Calcol se llenó de cólera y de ira contra él y dijo: ¿Por qué a otros reprendes y de reprenderte a ti mismo te olvidas? ¿No has escuchado lo que han dicho los sabios: adórnate a ti mismo y luego adorna a los otros [San 19a] ${ }^{26}$.

$\mathrm{Su}$ discurso cargado de furor, en lo que creo una intencionada emulación del discurso inicial del anciano, convierte al censor en censurado:

¡Dame, dame! dice y no le basta pues como una sanguijuela es su boca cuando come.

Mira su corazón se alza ante el trinar de un pájaro [Ecl 12: 4] mas para comer dientes de leoncillo tiene [Job 4: 10] ${ }^{27}$.

Tras estos versos satíricos, Falaquera parece no dejarnos mucho margen para pensar que hipocresía es el término adecuado para quien con aspecto y dichos de sabio enseña con sus palabras pero esta lejos de hacerlo

25 'Iggeret ha-musar, pág. 74.

26 Ibid.

27 'Iggeret ha-musar, pág. 74. El evitar comer en exceso, uno de los criterios básicos en el régimen de salud hipocrático, es también conducta propia del hombre sabio en la prosa medieval: «Ciencia y sabiduría no habitan en el vientre lleno ni en persona saciada» (Sefer ha-šă 'ašu 'im cap. XI, pág. 193; cito según la traducción castellana de M. ForTEZA REY, Libro de los entretenimientos (Madrid 1983); para el texto hebreo véase I. DAVIDSON, Sefer Shaashuim. A Book of Mediaeval Lore by Joseph ben Meir ibn Zabarra (New York 1914; reedición con prólogo en hebreo y adiciones, Berlin 1925). 
con sus obras ${ }^{28}$. Y si el maestro se ha convertido en hipócrita el aprendiz, Calcol, se ha transformado en maestro. No es ésta la única vez que asistimos a lo largo del texto a este juego de identidades que obliga a repensar el sentido de los personajes cuya ambigüedad es un rasgo que, entre otros, comparten algunos de los protagonistas del Sefer ha-měbbaque ${ }^{29}$.

De inmediato, con una escueta justificación ( «la saciedad no se siente con el pesar del hambre y yo durante varios días caminé por el desierto y no comí nada») ${ }^{30}$, el anciano vuelve a recuperar el papel de modelo y maestro que inicialmente se le había asignado. Se vale para ello del principio, presente en colecciones de castigos del XIII, de que ha de aprenderse de cada uno solo aquello por lo que es alabado ${ }^{31}$. De este modo un tanto forzado, Calcol se ve reducido de nuevo a la condición de discípulo y pasa a ser recriminado, aunque ahora de un modo más sereno, por la ira que ha manifestado hacia el anciano, ira cuyo control es lugar común al abordar cuestiones éticas y de moral práctica ${ }^{32}$.

Sin duda el sabio ha recuperado su función de guía, pero a mi modo de ver no se han despejado todas las dudas que nos obligan cuanto menos a sospechar, a mantenernos alerta ante el personaje si no por sus palabras sí por sus actos.

${ }^{28} \mathrm{Al}$ respecto, vale la pena recordar que en este ámbito ejemplar no basta con aprender los conocimientos y virtudes sino que hay también que ponerlas en práctica, pues el saber ha de asumirse con una dimensión práctica o, dicho en palabras de la época, «entender lo que dize e obrar por ello» (Libro del consejo y los consejeros, ed. de A. ReY, Zaragoza 1962, pág. 21).

${ }^{29}$ En este sentido resulta muy ilustrativo el personaje del médico, farsante y un buen conocedor de la ciencia que practica, quien actúa en este encuentro como contramodelo y modelo para el měbbaqueš. (Sefer ha-měbbaquěs, págs. 44 ss; The Book of the Seeker, págs. 40 ss.). Veáse también R. Brann, The Compuctious Poet. Cultural Ambiguity and Hebrew Poetry in Muslim Spain (Baltimore-London 1991) pág. 124 ss.

30 'Iggeret ha-musar, pág. 74.

${ }^{31}$ Así, entre otros, en Bocados de oro pág. 30, 11.21 ss.: «E dixo no aprendas de todos quanto ha enellos: mas conviene que aprendas de aquel que es alabado de todas sus maneras todo quanto ha enel y del que es alabado en una cosa aquella solamente».

${ }^{32}$ Un buen reflejo de ello son los relatos contenidos en el capítulo III («Del león et del buey») y XI («Del rey Ceredano et del su alguacil Beled et de su muger Elbed») del Calila e Dimna (edición de J. M. Cacho Blecua-M. a J. Lacarra, Madrid 1984). Para la versión hebrea de R. Yo'el, J. Derenbourg, Deux versions hébrä̈ques du livre de Kalîlâh et Dimnâh (Paris 1881). 


\section{LA MISOGINIA: UN SABIO CÉLIBE}

La cuestión que tras la comida se aborda nos lleva nuevamente a un terreno complejo y a un asunto especialmente controvertido en la obra de Falaquera: la actitud hacia las mujeres y, especialmente, hacia el matrimonio ${ }^{33}$. En principio nada tendría de extraño en el contexto socio-cultural de la época que el sabio manifestase una visión misógina al respecto; antes bien es esto lo que se espera a la luz de otros muchos testimonios literarios de la época ${ }^{34}$. Pero de nuevo el autor nos tiene reservada una sorpresa por el modo en que presenta el tema.

Al ser preguntado por Calcol sobre si tiene esposa e hijos ${ }^{35}$, el anciano comienza por lamentar el no haber gozado de los placeres de la juventud y

el no haber dado a las mujeres mi fuerza ${ }^{36}$ puesto que el flujo seminal del hombre es lo mejor de la sangre y es lo mejor del cuerpo ${ }^{37}$ porque Dios envió con él la preservación (de la vida) ${ }^{38}$.

Tras esta defensa de las relaciones sexuales en conexión con el texto bíblico y la obligación de procrear, su discurso da un giro para subrayar los peligros que comportan. Se apela con este fin a principios médicos bien conocidos desde la antiguiedad y desarrollados en los tratados de medicina medieval:

Y preguntaron al sabio: ¿Cuándo es el momento del coito? Y dijo: Cuando tú quieras debilitar tu cuerpo ${ }^{39}$. Y solía decir al rey de su

33 Véase Jospe, Torah and Sophia, págs. 143 ss.

${ }^{34}$ M. ${ }^{a}$ J. LACARrA, «Algunos datos para la historia de la misoginia en la Edad Media» en Studia in honorem prof. M. de Riquer, vol. I (Barcelona 1986) págs. 339-361. En el ámbito específico de la literatura hebrea T. Rosen, Unveiling Eve. Reading Gender in Medieval Hebrew Literatura (Philadelphia 2003).

35 'Iggeret ha-musar, pág. 75.

36 Versus Prov 31,3: «No gastes tu fuerza con las mujeres».

37 La misma idea se recoge en Versos para la sana conducción del cuerpo, págs. 84 y 26*: «Pues la simiente del hombre es su fortaleza».

38 'Iggeret ha-musar, pág. 75. Cf. Gn 45,5.

39 Cf. Musre ha-filosofim II, 19: 3 donde esta sentencia se atribuye a Aristóteles. 
tiempo: No te inclines hacia el coito pues él ahoga a los cerdos ${ }^{40} \mathrm{y}$ la mayoría de los seres humanos no mueren sino por esta causa ${ }^{41}$.

Este modelo de razonamiento que subraya el potencial dañino de la relación con las mujeres, capaces incluso de provocar la muerte, resulta habitual en la literatura sentenciosa de la época que se sirve de argumentos «científicos» para fundamentar su mensaje en contra de la desmesura sexual ${ }^{42}$. Sin duda, la lujuria no forma parte del modelo de individuo que en estas obras se propugna, pero nuestro sabio va a superar con mucho esta pretensión al declararse célibe: He hecho un pacto con mi alma: que no tendría mujer pues es ella herida incurable ${ }^{43}$. Esta negativa, no ya a mantener relaciones sexuales sino a tomar una esposa, no puede por menos que volver a llamar nuestra atención. Con ello el maestro esta contraviniendo uno de los principios del judaísmo y, en consecuencia, trasmitiendo a Calcol (y a un público judío) una enseñanza poco acorde, entre otros, con el propio Maimónides ${ }^{44}$. Si nada tiene de particular la imagen que Falaquera ofrece de la mujer al presentarla como un mal grave y una amenaza para la misma vida, un lugar común en los textos y colecciones de orientación didáctica que circulan por la Península ${ }^{45}$, no puede decirse lo mismo de esta decisión de permanecer célibe (al menos en un contexto judío) ${ }^{46}$.

${ }^{40}$ La comparación de quienes practican sexo con los cerdos (o las bestias en general) se repite en distintos escritos de Falaquera: así en Rešit Hoknmah (ed. D. Moritz, Berlin 1902; reimp. Jerusalem 1970, pág. 15) o en la 'Iggeret ha-halom (edición y traducción de S. CALDERER, en prensa, págs. 12 y 30); es, asimismo, un lugar común en las obras sapienciales del XIII: «Tal es el omne que biue a voluntad de su carne commo el puerco que e enbuelue en el lodo» (Los castigos del rey D. Sancho, cap. VI, pág. 102; «Alexandre, no querades fornicio seguyr, que es de natura de los puercos» (Poridat de las poridades, pág. 38; cito por el número de página de la edición de L. A. KASTEn, Madrid 1957).

41 'Iggeret ha-musar, pág. 75.

${ }^{42}$ Véase M. Haro Cortés, Los compendios de castigos del siglo XIII: Técnicas narrativas y contenido ético (Valencia 1995), pág. 250 ss.

${ }^{43}$ 'Iggeret ha-musar, pág. 75. Cf. Jr 15,18.

${ }^{44} \mathrm{La}$ actitud negativa que manifiesta hacia las relaciones sexuales en algunos de sus escritos no se usa, sin embargo, como argumento a favor del celibato. Véase Moreh ha-nĕbukim III, 8 (trad. castellana D. Gonzalo maeso, Guía de Perplejos, Madrid 1994) o Šémoneh pěraquim cap. IV (trad. castellana en C. DE VALLE, Maimónides. Ética, Madrid 2004).

45 En el ámbito hebreo baste con recordar los pasajes que se le dedican en Ben hamelek wĕ-ha-nazir cap. XXX o en Musre ha-filosofim II,1: 104.

${ }^{46}$ Es cierto que también Zeraḥ, protagonista del Minḥat Yěhudah de Ibn Šabbettay, defiende y opta por el celibato, pero al final de la obra el matrimonio es restituido plenamente como institución social. Véase Rosen, «Sexual politics». 
En este sabio de la 'Iggeret ha-musar pueden reconocerse paradigmas de conducta presentes en el pensamiento ascético medieval tanto árabe como cristiano, pensamiento que en su forma más extrema propugna la renuncia al matrimonio. No puede tampoco olvidarse que estamos en una época en la que se afirma la doctrina del celibato dentro de la Iglesia tras la prohibición de Calixto II del matrimonio del clero, cuestión que provocará un vivo debate. Además, la preocupación por las cuestiones sexuales se ha acrecentado entre los teólogos cristianos y en el pensamiento religioso de los siglos XII y XIII castidad y virginidad se ponderan como virtudes sobre la que discuten los maestros escolásticos ${ }^{47}$. Esta visión halla eco en los tratados sapienciales y libros de sentencias que insisten, entre otras cosas, en presentar la castidad como una de los valores que han de ornar y regir la vida del individuo ${ }^{48}$. Pero las posibles resonancias que este contexto socio-cultural pudiera tener en los círculos judíos ${ }^{49}$, no evita que el modelo que Falaquera está proponiendo resulte cuanto menos enigmático para una audiencia que, entre otras cosas, aun desconoce el origen y procedencia de este extraño maestro y que puede, pues, tenerlo por un miembro de su misma comunidad.

Cabe preguntarse si el autor se identifica con su personaje (y trata de que los destinatarios del texto también lo hagan), si les está ofreciendo una norma de comportamiento, una enseñanza a imitar; aun aceptando que los lectores judíos pudieron ver en el anciano asceta y célibe a un estereotipo no desconocido en la cultura del entorno, queda por saber si éste se les presentaba como un espejo en el que mirarse, como la imagen de un individuo «ideal» para su comunidad.

Mas, como sucede en tantas otras ocasiones, el autor se resiste a ofrecernos una respuesta única y, en una nueva muestra de ambivalencia, deja abierta la puerta a diversas interpretaciones. En este sentido resulta muy significativo que en la misma 'Iggeret ha-musar (pág. 91), una vez desaparecido el anciano, Calcol interrogue a Hemán sobre sus palabras y actos. $\mathrm{Y}$ esta actitud suya contraria al matrimonio es, precisamente, uno de los

${ }^{47} \mathrm{Al}$ respecto P. J. PAYER, The Bridling of Desire: Views of Sex in the Later Middle Age (Toronto-Buffalo 1993) especialmente cap. 7.

${ }^{48}$ Bien conocida es la reputación medieval de castidad que se atribuye a modelos de sabios como Platón o Sócrates e innumerables los ejemplos que de ello se recogen en los compendios de castigos (véase como muestra el Libro de los buenos proverbios, pág. 70).

49 Véase el sugerente estudio de Rosen, «Sexual politics». 
aspectos que se retoman y se releen en un intento, a mi parecer, de atenuar el desconcierto que pudo provocar y de conciliarlo con la propia tradición. Para ello se limita la opción del celibato a unos muy escasos sabios verdaderos y se recuerdan las razones tradicionales en pro del matrimonio (cuidado de la casa y procreación) necesario para la gran mayoría ${ }^{50}$. Mas en modo alguno se rechaza abiertamente la elección del personaje.

Al margen de esta cuestión, el resto de máximas que se dedican en este pasaje a subrayar la maldad de las mujeres son comunes en la literatura de la época con independencia de su procedencia. Valga como ejemplo de estas interconexiones culturales la siguiente anécdota, que ya utiliza Diogenes Laertius en el siglo III, y que se reelabora hasta la saciedad en textos europeos, árabes y, como en este caso, hebreos ${ }^{51}$ :

El hombre que tome mujer escriba en el dintel de su casa: «Que el mal no entre en esta casa». Y le dirán: Entonces que tu mujer no entre ${ }^{52}$.

\section{EN LA CASA DE ORACIÓN}

El momento de descubrir la identidad del sabio llega al ser interrogado por Hemán acerca de su procedencia. Es ahora cuando a los destinatarios de la 'Iggeret se les da a conocer su lugar de origen (la India) y su estirpe («los sabios de antaño») ${ }^{53}$. A modo de presentación autobiográfica, el personaje recuerda su vida solitaria, su entrega a la sabiduría y su posterior decisión de consagrarse a ella ante la necedad imperante pues

comprendí que al recorrer la tierra [Zac 4: 10] y difundir la Torah a los seres humanos, quizá podría separar el metal de la escoria $[\mathrm{Jr}$ 15: 19] y explicarles mi conducta en todo lugar al que fuese y decir a sus oídos palabras de ética y reprensión ${ }^{54}$.

Nuestro «asceta» se ha transformado en un predicador que marcha de

50 Véase 'Iggeret ha-musar, pág. 91 y s.

51 Unos años antes hará uso de ella Ibn Zabarra en el cap. 2 del Libro de los entretenimientos, pág. 31; Sefer Saashuim, pág. 89.

52 'Iggeret ha-musar, págs. 75-76.

53 'Iggeret ha-musar, pág. 76.

54 Ibid. 
un sitio a otro para hacer llegar un discurso edificante a quien quiera oírlo. Recordemos que en el siglo XIII no es ésta una imagen extraña pues, especialmente a partir del Concilio de Letrán (1225), se recomienda prestar una mayor atención a la instrucción del pueblo y las plazas y calles se van llenando de predicadores que tratan de conducir a los presentes al camino recto. La proliferación de tratados de preceptiva aplicados al discurso homilético y la aparición de las «Ars predicandis» son el mejor testimonio de la intensificación de esta actividad ${ }^{55}$ que, entre otras cosas, se convierte en un arma para alentar a la conversión. Mucho más llamativo resulta el modo en que Falaquera prosigue su relato: Hemán «reúne a todas a las gentes del lugar»y «los convoca a la casa de oración»(bet ha-tĕfilah); pero no lo hace para que asistan a un oficio religioso o aprendan de un rabino sino para que escuchen al sabio hindú «porque es bueno lo que tú has dicho» ${ }^{56}$. Y el anciano se dirige allí y se sitúa "sobre el pueblo» ( 'al ha- 'am), en una más que probable alusión a la tebah desde donde se pronuncian en las sinagogas los sermones. La escena que Falaquera nos dibuja sobrecoge (un espacio de oración judío, un maestro judío y al frente un hindú) y lo hace aún más si pensamos en otra imagen bien distinta: la de sinagogas (y mezquitas) como escenarios forzosos de prédicas de monjes cristianos que tratan de convertir a su audiencia con un arsenal de argumentos y acusaciones ${ }^{57}$.

En este marco el pandit hindú va a tomar la palabra para censurar a su público valiéndose de un discurso construido por una sucesión de citas bíblicas mediante el recurso a la técnica del engarce. En él no se emplean exempla, ni dichos o sentencias de origen secular como sucede en el resto de la obra. Todo el mensaje se elabora con versículos tomados de la Biblia con los cuales se increpa a la asamblea con dureza, se le acusa de abandonar la sabiduría y la rectitud, de refugiarse en la riqueza, de hacer el mal, de despreciar la ética; se le recuerda los castigos que les aguardan de persistir en su conducta, se exhorta al arrepentimiento poniendo frente a ellos la realidad de

55 Véase J. J. Murphy, La Retórica en la Edad Media: historia de la teoría de la retórica desde S. Agustín hasta el Renacimiento (México 1986), especialmente cap. VI.

56 'Iggeret ha-musar, pág. 76.

${ }^{57}$ Especialmente con la aparición de dominicos y franciscanos las prédicas en mezquitas y sinagogas se convierten en un instrumento habitual en pro de la conversión. Estas órdenes mendicantes iniciaran en el siglo XIII una campaña intensa que obliga a judíos y musulmanes a reunirse para escuchar sus sermones, actividad que no pocas veces desemboca en actos de violencia por parte de los cristianos que acompañan al predicador. 
la muerte. En los destinatarios de esta prédica se ha proyectado un modelo de individuo, y de grupo, rechazable desde todo punto, radicalmente alejado de todo modelo ético. Por su parte, el orador ha demostrado conocer bien cómo captar a su auditorio, cómo mantener su interés, cómo persuadirlo y conmoverlo hasta, según el texto nos dice, provocar el llanto:

Y sucedió que cuando el pueblo oyó [Jos 6: 20] estas palabras, todos empezaron a llorar desde los pequeños hasta los mayores [ $\operatorname{Jr} 6: 13$ ]. Entonces Hemán hizo callar al pueblo ${ }^{58}$ y les dijo: Escuchad las palabras del anciano y prestad atención [Is 55: 3] a sus reproches; quizá mejoréis ${ }^{59}$.

Aunque de modo mucho más breve, el maestro de la India interviene una segunda vez ante la asamblea contraponiendo la sabiduría a la necedad, proclamando la fuerza de un saber capaz de hacer frente a los peligros del mundo, de asegurar la perfección interior e incluso la vida futura ${ }^{60}$. El proceso de conversión se consuma, pues el personaje no sólo consigue ganarse la voluntad de su audiencia sino también modificar su conducta:

«Respondió todo el pueblo diciendo [Esd 10: 12] ¡Nos has dado la vida! [Gn 47:25]. El camino de la verdad nos has enseñado, aceptamos también tus advertencias y haremos como nos mandas» ${ }^{61}$

La singularidad de este pasaje no reside tanto en lo que se enseña (pautas de conducta de validez universal), sino en quién y dónde se hace. En un plano literario estamos ante un hábil recurso si lo que se trata es de mantener la atención de los receptores de la obra; pero en este tipo de tratado que se propone enseñar con lo que los personajes hacen (y no sólo con lo que dicen), la elección del marco escénico y de los protagonistas son en sí mismo un mensaje portador de significado.

${ }^{58}$ Como Caleb hizo ante Moisés. Cf. $\mathrm{Nm}$ 13: 30.

59 'Iggeret ha-musar, pág. 77.

${ }^{60}$ Ideas análogas se encuentran en textos sapienciales del medievo donde el saber y el obrar recto son garantía de inmortalidad. Véase el prólogo del Sendebar, pág. 63-64 (edición de M. ${ }^{a}$ J. Lacarra, Madrid 1996. Para la versión hebrea M. Epstein, Tales of Sendebar. An Edition and Translation of the Hebrew Version of the Seven Sages, Philadelphia 1967).

${ }^{61}$ 'Iggeret ha-musar, pág. 77. 


\section{LA MUERTE DEL SABIO: LA VERDAD DEL OTRO}

Continúa Falaquera manteniendo al anciano como protagonista de su relato, un anciano que ahora enferma provocando con ello la preocupación de Calcol. El diálogo que al respecto entablan ambos personajes es, en mi opinión, clave para comprender las intenciones de autor:

Le dijo el anciano: ¿Por qué te preocupas? Le respondió: Me preocupa que puedas morir en tierra extraña. Le dijo el anciano: No te preocupes pues yo soy viejo y estoy lleno de canas [1 Sm 12: 2]; estoy saciado de este mundo y no hay diferencia entre que muera el hombre en tierra extraña o que muera en su tierra pues el camino hacia el mundo futuro es uno desde todos los lugares ${ }^{62}$.

Tal afirmación de «universalismo» resulta llamativa en un contexto judío, donde el tema de la tierra juega un papel central. La honda conexión con la patria de los antepasados forma parte de los anhelos compartidos por la comunidad y la nostalgia que provoca es tema habitual en la literatura hebrea, sobre todo en la poesía litúrgica. La idea de un camino común «hacia el mundo futuro» en el que se diluyen las fronteras entre territorios y patrias contrasta con los deseos intensos de morir en Jerusalén que personalidades judías como Yĕhudah ha-Levi expresaron con fuerza y belleza en sus versos ${ }^{63}$. En boca de un hindú, de un extranjero, se han puesto palabras que mitigan la importancia del lugar en el que llegue la muerte; la situación del personaje no es muy distinta de la del público de la 'Iggeret: también ellos se encuentran lejos de la Tierra Prometida y, tal vez, al igual que a Calcol, les angustie la idea de acabar sus días en tierra extraña.

Las diferencias que en principio separaban al extranjero procedente de la lejana India de la audiencia hebrea se han ido haciendo cada vez menos relevantes y acaban borrándose tras la muerte («el camino hacia el mundo futuro es uno»). No es ésta la única vez que Falaquera reivindica el valor del otro, de los sabios «gentiles». Siguiendo la estela de Maimónides

62 'Iggeret ha-musar, pág. 78.

${ }^{63}$ Especialmente en sus conocidos poemas de Sión, poemas del mar y poemas de Egipto. Véase A. Sáenz-Badillos-J. Targarona Borras, Yehudah ha-Levi. Poemas (Madrid 1994) págs. $411 \mathrm{ss.}$ 
(«iescucha la verdad de quienquiera que la anuncie!») ${ }^{64}$, Šem Tobinsiste a lo largo de sus escritos en este principio que subraya el carácter universal de la verdad con independencia de quien la proclame, sin importar su origen ni sus creencias ${ }^{65}$.

Y desde esta perspectiva, nada mejor para ilustrar este pensamiento que encarnarlo en alguien distinto y extraño: un extranjero, asceta extremo, célibe, con sombras en su conducta, etc., pero a pesar de todo ello, capaz de enseñar, de mover al arrepentimiento. Falaquera ha llegado lejos en su propuesta, ha creado a un personaje capaz de trasmitir sabiduría de una manera nada convencional, un maestro cuya aceptación como tal exige un talante abierto por parte de los destinatarios de la obra y que, muy probablemente, no sería del agrado de todos los sectores judíos del siglo XIII.

Ya en su lecho de muerte el anciano va a ofrecer, a petición de Calcol, sus últimas enseñanzas ${ }^{66}$. A modo de testamento se inserta en el texto un compendio de saber tradicional basado en la idea aristotélica del justo medio, idea que contrasta con el tipo de vida por la que el hindú ha optado y que vuelve a subrayar lo paradójico de su carácter. Con materiales que forman parte del legado común de la literatura sapiencial, se ofrecen una serie de principios básicos que han de regir la conducta humana (la moderación, el sosiego, la virtud del buen consejo), en línea con el pensamiento que Falaquera defiende en su obra por boca de Hemán.

Tras estas recomendaciones finales, el sabio muere en una escena con unas nada inocentes resonancias bíblicas: rodeado de todo el pueblo como Abrahám [Gn 25: 17], enterrado en un sarcófago como José [Gn 50: 27] y llorado con una impresionante qinah como el mismo rey David lloró a Saúl y a su hijo [2 Sm 1: 17], así llega al término de sus días este sabio procedente de la India:

Y murió el anciano y se reunió con su pueblo. Se congregó entonces todo el pueblo y lo lloraron, lo honraron, lo embalsamaron y lo

${ }^{64}$ Del Valle, Maimónides. Ética, pág. 59.

${ }^{65}$ Cf. 'Iggeret ha-Vikuah, pág. 13 (cito según la edición de S. HARVEY, Falaquera's Epistle of the Debate. Critical edition with annotated English translation, Cambridge/ Mass.-London 1987); trad. española A. SÁEnz-BADIllos, 1993, «La Carta del debate de Sem Tob ibn Falaqera», MEAH 42,2 (1993) págs. 105-133; Versos para la sana conducción del alma 113 y 61*; Sefer ha-Ma ălot, págs. 11-12 (ed. L. Venetianer, Berlin 1984; reimpr. Maqor, Jerusalén 1970).

66 'Iggeret ha musar, pág. 78. 
pusieron en un ataúd. Hemán entonó este lamento fúnebre por el anciano:

Temblad los despreocupados [Is 32: 11], pues los fieles han desaparecido [Sal 12: 2]; ha caído el poderoso, se humilla el soberbio [Job 40: 11]; una estrella se ha oscurecido, la fuente de la justicia se ha cegado, ha desaparecido el hombre recto [Is 57: 1]; por esto lloraré amargamente [Is 22: 4] y ofreceré una endecha: ¡Ay de aquel día! [ $E z$ 30: 2] ¡Cómo han asolado la grandeza [ $Z a$ 11: 3], ha caído la corona [Lam 5: 15], ha sido quebrantado el orgullo de su fuerza [Le 26: 19]! Una estrella en la tierra ha sido enterrada y por eso nuestros ojos derraman lágrimas [Je 9: 17], por eso nuestro corazón arde en ira [Dt 19: 6]. Nosotros, hijos del hombre, sepamos que gusanos somos [Sal 22: 7], que al še'ol nos dirigimos, que en la oscuridad extenderemos nuestro lecho [Job 17: 13] y nuestra almas serán rescate del še ol; enderecemos nuestras sendas [Pro 3: 6] arrepintámonos de nuestros pecados [Ez 33: 14] y unámonos a Dios, el lleno de gloria, el terrible, que es refugio en tiempos de angustia [Sal 9: 10] ${ }^{67}$.

Estas expresiones de dolor ante su desaparición contribuyen a enaltecer la figura del personaje al tiempo que, en un uso común, la muerte se convierte en un efectivo recurso didáctico. Sin embargo, el pesar por su pérdida no es óbice para que de inmediato Calcol interrogue a Hemán sobre este sabio ${ }^{68}$. ¿Por qué este interés ahora por conocer la opinión del maestro? ¿Qué desea saber el joven cuando el anciano hindú ya no le escucha? Las palabras de Hemán no dejen lugar a dudas respecto a la consideración que le merece el personaje: En verdad era uno de los hombres de sabiduría y sus dichos muestran que frecuentaba a los hombres de ética; comprendí que era un hombre limpio de dos maldades que son la envidia y la mentira ${ }^{69}$. El maestro judío está avalando con su autoridad la rectitud del maestro de la India, lo está legitimando ante su discípulo al incluirlo sin titubeos en el grupo de los hombres sabios. Mas la ponderación de sus virtudes parece no ser suficiente para explicar algunos aspectos de su conducta, especialmente su renuncia al matrimonio que, como ya antes

67 Ibid.

68 «Después preguntó Calcol a Hemán sobre este anciano»: 'Iggeret ha musar, pág. 90.

69 Ibid. La alusión a la envidia y a la mentira tienen por objeto facilitar la inserción de una serie de enseñanzas respecto a dos de los rasgos vilipendiados en la colecciones de castigos medievales. 
se ha señalado, Hemán tratará de conciliar con la propia tradición. Este esfuerzo final de Falaquera por «defender» a su personaje es, en mi opinión, la mejor prueba de que estamos ante un modelo desconcertante. La impresión de perplejidad que el anciano hindú causa al joven Calcol no debió de ser ajena a los lectores del momento. El autor los hace (y nos hace) enfrentarnos a un perfil de individuo que resulta difícil identificar, sobre todo por su actuación, con un paradigma convencional de sabio; en él, es cierto, se reúnen, enseñanzas universales pero también otras más difíciles de aceptar en un contexto judío.

¿Qué pretendía Falaquera con ello? No parece que su propuesta sea la de presentarlo como modelo ideal y único en el que la comunidad toda hubiera de inspirarse, pero sí como un portador de valores a tener en cuenta. El talante abierto de Šem Tob se personifica en este anciano singular por sus dichos y sus obras, con contradicciones en su conducta, con ecos de tipos sociales no necesariamente judíos, etc., pues lo que realmente importa es que se trata de un sabio, de alguien que ha adquirido conocimiento y que es capaz de trasmitirlo, lo que realmente importa es que Calcol aprenda «que no hay hombre sino por su intelecto y su sabiduría, que no hay humano sino por su saber y entendimiento» ${ }^{70}$, «que la compañía de los sabios es más valiosa que las perlas» ${ }^{71}$.

Pienso que Falaquera está proponiendo una concepción del saber que lleva implícita la defensa de la apertura universalista a la verdad, una idea que se deja sentir con fuerza, y no sin polémica, en el pensamiento hispanojudío a lo largo de la Edad Media ${ }^{72}$. Y este aserto filosófico cobra vida en el sabio de la India, su imagen y sus paradojas son en sí mismas la mejor ilustración de la aseveración maimonidiana de aceptar la verdad de quien quiera que la enuncie. Falaquera ha encontrado un modo de comunicar una opinión filosófica con una expresión literaria de probado valor didáctico, de conjugar su defensa de la autonomía de la verdad con su quehacer como creador de textos que deleitan, de invitar con su relato a despojarse de prejuicios hacia el otro, a aceptar un trasvase de saberes, a abrirse a otras formas de conocimiento.

70 'Iggeret ha-musar, pág. 77.

71 'Iggeret ha-musar, pág. 86.

72 Un interesante acercamiento a esta premisa filosófico-racionalista puede verse en L. M. Girón-Negrón, «La rosa y el espino de Santob de Carrión: breve nota sobre un motivo filosófico», en Dejar hablar a los textos. Homenaje F. Márquez Villanueva, ed. P. M. Piñero Ramírez, vol. I (Sevilla 2005) págs. 251-259. 


\section{RESUMEN}

Se estudia en este artículo a uno de los protagonistas de la 'Iggeret ha-musar de Šem Tob ibn Falaquera: el maestro hindú. Este personaje se revela en el texto como un sabio extraño y controvertido por sus palabras y, sobre todo, por su conducta. A través de él se enseñan principios universales bien conocidos en las colecciones de castigos del siglo xiii; pero también actúa como portador de mensajes que resultan llamativos en un contexto judío y que hacen necesario interrogarse acerca de su función en la obra y los valores que a través de él el autor defiende. Su análisis contribuye a iluminar el pensamiento de Falaquera así como el clima socio-cultural de su tiempo.

Palabras Clave: Literatura didáctica, siglo XIII, Šem Tob ibn Falaquera, 'Iggeret ha-musar.

\section{SUMMARY}

This article analyzes one of the main characters of the 'Iggeret ha-musar by Shem Tov ibn Falaquera: the Hindu master. In the text this figure shows himself as a strange and controversial wise man by his words and, especially, by his behaviour. He is used by the author to teach ethical concepts well-known in the didactics literature of the thirteenth century; but he also offers messages that could be considered inusual in a Jewish context. This circumstance makes necessary to ask us about his function within the treatise and the values that the author defends through him. This analysis will contribute to illuminate Falaquera's thought as well as the sociocultural climate of his time.

KEYwords: Didactic Literature, $13^{\text {th }}$ Century, Šem Tobibn Falaquera, 'Iggeret ha-musar. 